\title{
Tantangan Analisis Kebijakan Pencegahan Kekerasan Seksual Terhadap Anak Dengan Mengembangkan Media Teknologi Informasi
}

\author{
Sri Siswati ${ }^{*}$, Yulia Hartati², Nizwardi Jalinus ${ }^{3}$ \\ 1,2,3 Fakultas Kesehatan Masyarakat Program Studi Ilmu Kesehatan Masyarakat Universitas Andalas Padang
}

\author{
A R T I C L E I N F O \\ Article history: \\ Received 19 February 2018 \\ Received in revised form \\ 10 March 2018 \\ Accepted 12 April 2018 \\ Available online 25 May \\ 2018 \\ Kata Kunci: \\ Tantangan, Kekerasan \\ seksual pada anak, Inovasi, \\ Future Mind Set \\ Keywords: \\ Challenges, Sexual Violence \\ on Children, Innovation, \\ Future Mind Set
}

\begin{abstract}
A B S T R A K
Tujuan penelitian ini melihat tantangan dari hasil analisis pencegahan kekerasan seksual terhadap anak. Desain penelitian adalah metode kualitatif, dilakukan di P2TP2A pada bulan Oktober 2017 sampai Maret 2018. Pengumpulan data dilakukan dengan wawancara mendalam, FGD, observasi dan telaah dokumen. Informan penelitian ditentukan berdasarkan purposive sampling. Analisis data dilakukan dengan triangulasi metode, dan sumber. Tantangan ke depan dibahas berdasarkan referensi dan hasil analisis penelitian. Hasil penelitian diperoleh tenaga mencukupi, dana dan sarana prasarana masih kurang. Pencegahan primer dan sekunder belum semua sekolah seperti deteksi dini kasus, pemberian konseling serta penanganan korban kekerasan. Kesehatan adalah sehat fisik, mental, social dan spiritual. Dari hasil penelitian, tantangan ke depan pecegahan primer tidak terbatas pada anak, tetapi juga guru dan orang tua, dan dimulai sejak anak-anak masih kecil yang disesuaikan dengan perkembangan teknologi. Teknologi yang berkembang pada zaman revolusi industri 4.0 adalah teknologi informasi melalui berbagai aplikasi media sosial, seperti instagram, facebook, washapp, ad modo, I learning dan sebagainya.
\end{abstract}

\section{A B S T R A C T}

The purpose of this study saw the challenges of the results of the analysis of prevention of sexual violence against children. The research design is a qualitative method, carried out in P2TP2A in October 2017 to March 2018. Data collection is done by in-depth interviews, FGDs, observation and document review. The informants of the study were determined based on purposive sampling. Data analysis is done by triangulation methods, and sources. The future challenges are discussed based on the references and the results of the analysis of the research. The results of the research are sufficient, the funds and infrastructure are lacking. Primary and secondary prevention not all schools such as early detection of cases, giving counseling and handling victims of violence. Health is physically, mentally, socially and spiritually healthy. From the results of the study, the future challenges of primary prevention are not limited to children, but also teachers and parents, and began as young children who were adapted to technological developments. The technology that developed in the era of industrial revolution 4.0 was information technology through various social media applications, such as Instagram, Facebook, Washapp, Ad Modo, I learning and so on.

\footnotetext{
* Corresponding author.

E-mail addresses: srisiswati@yahoo.co.id (Sri Siswati)
} 


\section{Pendahuluan}

Miris sekali melihat meningkatnya kekerasan seksual yang terjadi di Indonesia. Kekerasan seksual terhadap anak ibarat fenomena gunung es, sedikit yang terlihat namun masih banyak kasus yang belum terungkap Dalam 3 tahun terakhir meningkat tajam, tahun 2013 terdapat 1445 kasus, 2014 terjadi 1423 kasus dan puncaknya tahun 2015 meningkat tajam menjadi 1718 kasus, dan ini mengisyaratkan Indonesia sudah memasuki masa darurat. Menurut Konsultan Pemberdayaan Perempuan dan Anak, Sumatera Barat menempati peringkat ke 3 kekerasan seksual terhadap anak dan perempuan. Tahun 2014 terjadi 314 kasus. Tahun 2015 sebanyak 331 kasus dan sedikit menurun tahun 2016 sebanyak 325 kasus. atau $60 \%$ dari kekerasan seksual terhadap anak $60 \%$ adalah kekerasan seksual . Tujuan penelitian ini untuk melihat analisis kebijakan UU Nomor 35 Tahun 2014 tentang Perlindungan Anak.

Kekerasan seksual terhadap anak memiliki dampak yang sangat serius bagi perkembangan anak, menyisakan luka fisik dan trauma mendalam. Penelitian M.Anwar Fuadi (2011), anak yang menjadi kekerasan seksual akan mengalami dampak psikologis berupa stress pasca trauma, bisa berupa perubahan mood dan perilaku, penilaian diri yang rendah, pengabaian pada diri sendiri, kenangan yang tidak pernah hilang, gangguan tidur dan lain sebagainya. $82 \%$ anak yang mengalami kekerasan seksual tidak mampu melupakan kejadian yang dialaminya dan $30 \%$ korban memiliki gangguan kejiawaan dengan adanya keinginan untuk bunuh diri

Kota payakumbuh merupakan kota dengan kekerasan seksual tertinggi setelah Kabupaten Agam dan Solok di Sumatera Barat pada tahun 2016. Selama 3 tahun terakhir di payakumbuh terjadi peningkatan 4 kasus pada tahun 2014, 20 kasus pada tahun 2015 dan 28 kasus pada tahun 2016. Selama tahun 2017 periode Januari-Oktober, Polres kota Payakumbuh sudah menerima sebanyak 8 laporan kekerasan seksual terhadap anak dengan 4 laporan anak usia 16-18 tahun, 3 pada anak usia 13-15 tahun serta 1 orang anak usia 6-11 tahun. Kasus bervariasi mulai pencabulan sampai perkosaan. Anak remaja sangat rentan mengalami kekerasan seksual atau sebagai pelaku kekekrasan seksual

Lembaga yang menjadi leading sector dalam pencegahan kekerasan seksual pada anak adalah Pusat Pelayanan terpadu Pemberdayaan Perempuan dan Perlindungan Anak (P2TP2A), dengan tugas pokok dan fungsinya melakukan upaya pencegahan dan penanganan terhadap korban kekerasan terhadap perempuan dan anak. P2TP2A di Sumatera Barat sudah terbentuk di seluruh kabupaten/kota dengan kondisi yang sangat bervariasi. Fokus tugasnya pemberian pelayanan penanganan kasus dan korban kekerasan melalui kegiatan konseling, pendampingan, pendidikan dan pelatihan. Hanya sedikit yang dapat melakukan fungsi pencegahan dan pemberdayaan .

Wawancara dengan petugas P2TP2A terdapat beberapa kendala dalam upaya pencegahan kekerasan seksual pada anak antara lain belum memiliki gedung sekretariat sendiri sehingga pelayanan kurang optimal dan masyarakat tidak mengenal P2TP2A tersebut. Tenaga masih bersifat sukarela yang berasal antara lain organisasi kemasyarakatan, tenaga P2TP2A serta perorangan yang peduli dengan masalah ini. Dana yang tersedia tidak mencukupi, promosi kesehatan hanya terbatas pada 2 anak per kelas disamping kepala sekolah, guru dan staf. Tidak ada poster dan baliho untuk masyarakat terutama orang tua anak. Mengingat P2TP2A adalah lembaga pemerintah daerah perlu optimalisasi tugas pokok dan fungsinya.

Pada revolusi industry 4,0, pencegahan kekerasan seksual membutuhkan penyesuaian aplikasi cara pikir dalam mengatasinya, dan ini merupakan tantangan yang harus dihadapi. Tujuan penelitian ini melihat tantangan dari hasil analisis pencegahan kekerasan seksual terhadap anak yang terjadi di kota Payakumbuh tahun 2017. Tujuan khusus untuk mengetahui input, proses dan ouput yang dihasilkan. Manfaat penelitian bagaimana agar P2TP2A dan pemerintah daerah menghadapi tantangan aplikasi pencegahan terjadinya kekersan seksual pada anak.

\section{Metode}

Penelitian dilaksanakan dengan metode kualitatif dengan pendekatan system untuk menggali informasi mendalam dalam analisis Pelaksanaan Pencegahan Kekerasan Seksual Terhadap Anak di Pusat Pelayanan Terpadu Perlindungan Perempuan dan Anak (P2TP2A) kota Payakumbuh. Wawancara mendalam dilakukan kepada Wakil Ketua P2TP2A, Ketua Devisi, Petugas P2TP2A, Kepala Sekolah/Guru BP. Fokus Grup Diskusi dilakukan pada siswa sekolah dengan peralatan seperti tape rekorder, buku catatan dan camera. Dilakukan tringulasi metode, data dan observasi. 


\section{Hasil dan pembahasan}

Menurut Erlinda, kekerasan seksual pada anak terdiri dari 3 tingkatan yaitu pencegahan primer antara lain dengan melakukan edukasi dan layanan proteksi sesuai usia anak, pencegahan sekunder dengan deteksi dini kasus, konseling keluarga dan penanganan kasus serta pencegahan tersier dengan rehabilitasi dan persiapan kembali kepada lingkungan social dan komunitasnya. Strategi pencegahan dilakukan melalui perlindungan diri bagi anak dengan menanamkan rasa aman, memberikan informasi pada anak mengenai kekerasan, memahami situasi lingkungan sekitar pada anak, menilai tempat yang aman dan tidak aman, bersikap waspada pada orang dewasa asing disekitarnya, mengenali dan menyadari tanda-tanda bahaya awal, dan mencari langkah-langkah penyelamatan diri. Kedua, memberikan pendidikan perlindungan kekerasan seksual dengan mengajarkan pada anak bagian tubuh yang bersifat pribadi, mengenali jenis sentuhan yang bersifat pribadi, mengajari anak untuk berkata tidak pada sentuhan yang tidak diinginkan dan mencari langkah-langkah penyelamatan diri.

Pencegahan primer terdapat banyak elemen dalam program preventif dengan 3 sasaran promosi atau preventif yaitu. Dalam memberikan preventif ini ada 3 sasaran primer, sekunder dan tersier. Primer meliputi kelompok masyarakat yang akan diubah perilakunya seperti anak sekolah, remaja, guru di sekolah dan masyarakat umum. Sekunder tokoh masyarakat, panutan msyarakat serta tersier pembuat keputusan di tingkat local seperti camat, bupati, atau pejabat pemerintah setempat. Pencegahan sekunder berkaitan dengan deteksi dini kasus, konseling keluarga dan konseling lanjutan dari kasus yang terjadi.

Hasil dari penelitian dari segi input yang meliputi tenaga, dana, sarana dan prasaran, serta metode yang digunakan. Segi proses kegiatan yang dilakukan serta melihat output jumlah kasus kekersan seksual terhadap anak yang terjadi. Pengumpulan data diperoleh dari metode wawancara mendalam. FGD serta telaahi dokumen/dan dan data yang tersedia. Sesuai dengan metode penelitian analisis dilakukan triangulasi data dan metode dari system yang input, proses dan output.

Matrik Triangulasi Input dapat dilihat dari table dibawah ini :

Tabel 1. Matrik Triangulasi Komponen Input

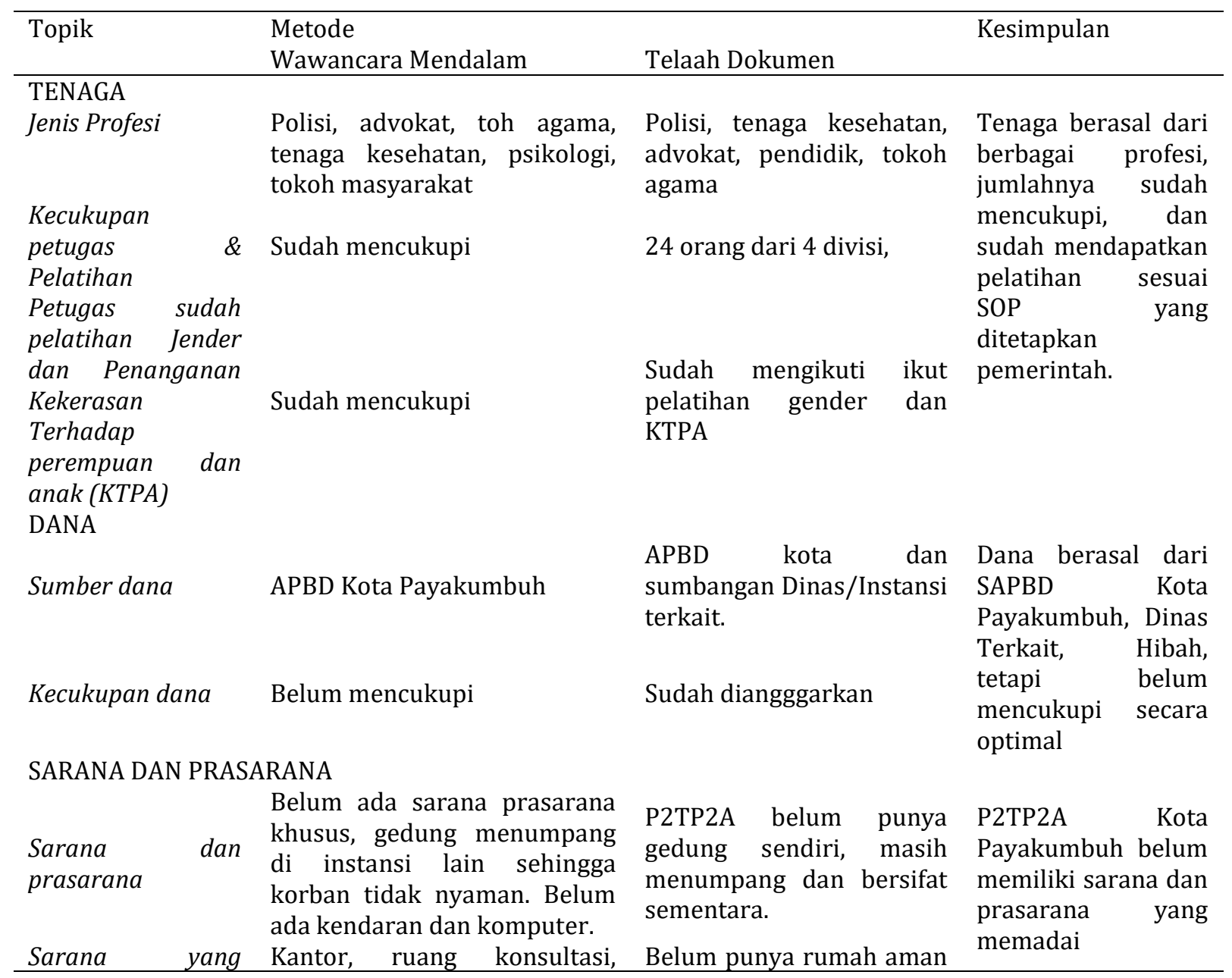




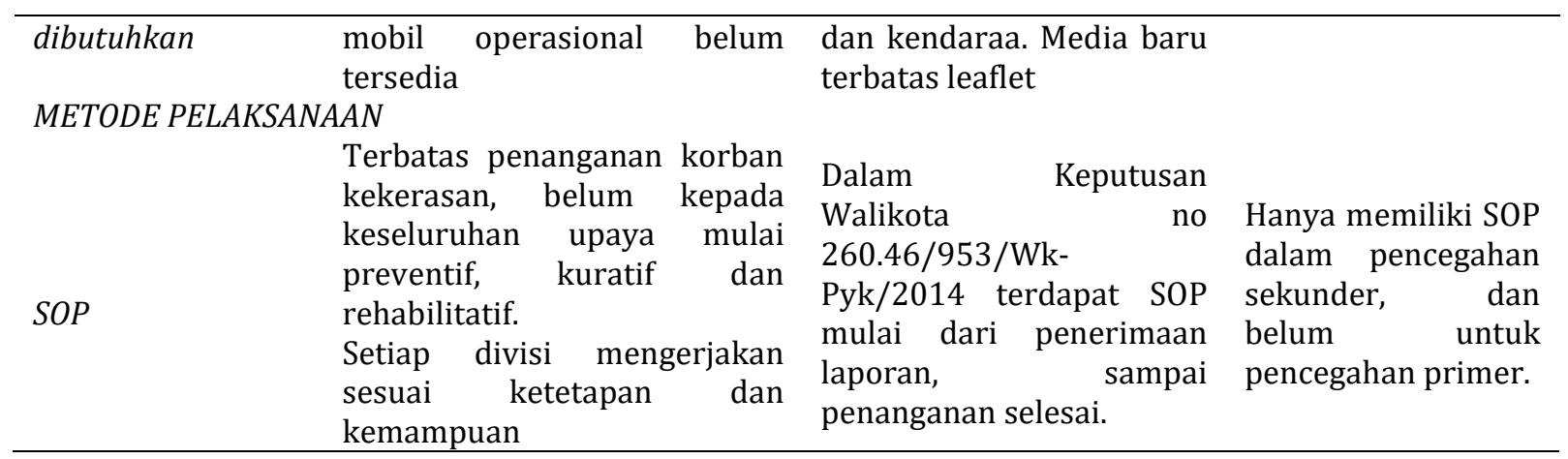

Tabel 2. Matrik Triangulasi Komponen Proses

\begin{tabular}{|c|c|c|c|}
\hline Topik & $\begin{array}{l}\text { Metode } \\
\text { Wawancara Mendalam }\end{array}$ & FGD & Kesimpulan \\
\hline $\begin{array}{l}\text { Pencegahan } \\
\text { Primer }\end{array}$ & $\begin{array}{l}\text { - P2TP2A Kota Payaumbuh } \\
\text { memberikan Edukasi tentang } \\
\text { kekerasan seksual dan } \\
\text { pencegahannya } \\
\text { - Memberikan pengenalan } \\
\text { terhadap kekerasan seksual } \\
\text { - Mengadakan pelatihan } \\
\text { tentang penerimaan kasus } \\
\text { kekerasan terhadap } \\
\text { perempuan dan anak } \\
\text { - Pelaksanaan seminar }\end{array}$ & $\begin{array}{ll}\text { Tahun } 2017 \text { telah melakukan } \\
\text { sosialisasi, penyuluhan dan } \\
\text { monitoring } & \text { ke-sekolah- } \\
\text { sekolah, seperti } & \text { SMP, SMK, } \\
\text { dan MAN } & \end{array}$ & $\begin{array}{lr}\text { Pencegahan } & \text { primer } \\
\text { diberikan } & \text { melalui } \\
\text { penyuluhan } & \text { dengan } \\
\text { dihadiri } & \text { tokoh } \\
\text { masyarakat } & \text { dan } \\
\text { organisasi lainnya. } \\
\text { Hanya terbatas pada } \\
\text { penyuluhan setingkat } \\
\begin{array}{l}\text { SLTA dan sekolah } \\
\text { negeri. }\end{array}\end{array}$ \\
\hline $\begin{array}{l}\text { Pencegahan } \\
\text { Sekunder }\end{array}$ & $\begin{array}{l}\text { - Hanya menerima laporan } \\
\text { dari kepolisian, monitoring } \\
\text { evaluasi ke sekolah } \\
\text { - Observasi kekerasan yang } \\
\text { dialami korban } \\
\text { - Pemberian konseling oleh } \\
\text { tenaga kesehatan jika } \\
\text { dibutuhkan }\end{array}$ & $\begin{array}{l}\text { Menangani kasus sesuai } \\
\text { laporan, mulai dari mencatat, } \\
\text { assesment, serta konseling }\end{array}$ & $\begin{array}{l}\text { Pencegahan terbatas } \\
\text { deteksi dini kasus, } \\
\text { konseling dan } \\
\text { penanganan korban }\end{array}$ \\
\hline
\end{tabular}

Tabel 3. Matrik Triangulasi Komponen Out Put

\begin{tabular}{|c|c|c|c|}
\hline TOPIK & $\begin{array}{l}\text { METODE } \\
\text { Wawancara Mendalam }\end{array}$ & Telaah Dokumen & Kesimpulan \\
\hline $\begin{array}{l}\text { Penyebab } \\
\text { Meningkatnya } \\
\text { kssus } \\
\text { kekerasan } \\
\text { seksual }\end{array}$ & $\begin{array}{l}\text { Pengawasan orang tua kurang, } \\
\text { pengaruh lingkungan dominan, } \\
\text { pergaulan bebas, terbatas sarana } \\
\text { dan prasarana di P2TP2A }\end{array}$ & $\begin{array}{l}\text { Terdapat } 9 \text { kasus yang } \\
\text { dilaporkan ke kepolisian, } \\
\text { dan } 1 \text { ke P2TP2A }\end{array}$ & $\begin{array}{l}\text { Dana yang kurang, } \\
\text { minimnya sarana dan } \\
\text { sosialisasi yang kurang }\end{array}$ \\
\hline Kendala & $\begin{array}{l}\text { Sulit sosialisasi dengan orang } \\
\text { tua, masalah merupakan aib dan } \\
\text { tidak dilaporkan, sarana dan } \\
\text { prasarana pencegahan kurang, } \\
\text { belum semua upaya yang } \\
\text { dilakukan yaitu preventif, } \\
\text { promotif, kuratif dan } \\
\text { rehabilitatif }\end{array}$ & & $\begin{array}{ll}\text { Mindset } & \\
\text { penanggulangi } & \text { adanya } \\
\text { kekerasan } & \text { seksual } \\
\text { perlu dirubah. } & \end{array}$ \\
\hline
\end{tabular}

Melihat hasil penelitian di atas, kita dapat melihat bahwa pemerintah telah melaksanakan berbagai program dan kegiatan dalam mendukung hak anak dan perlindungan kepada anak seperti Pengembangan program Kota Layak Anak (KLA), Sekolah ramah anak, pembentukan forum anak tingkat provinsi dan 
kabupaten/kota, penyediaan ruang pengadilan ramah anak, promosi berupa gerakan perlindungan anak. Secara nasional juga ada Anti Kekerasan Terhadap Anak (GN-AKSA).

Berdasarkan kebijakan pemerintah terakhir yaitu UU Nomor 35 Tahun 2014 tentang Perlindungan Anak, bahwa pemerintah bertanggung jawab menyediakan fasilitas pelayanan untuk perlindungan anak. Salah satunya adalah adanya Pusat Pelayanan Terpadu yang merupakan suatu unit kerja fungsional yang merupakan pelayanan terpadu unuk korban tindak kekerasan.

Berdasarkan Instruksi Presiden Nomor 5 Tahun 2014 tentang Gerakan Nasional Anti Kekerasan Terhadap Anak dengan terbentuknya suatu lembaga yang melakssanakan pencegahan dan pemberantasan kejahatan seksual terhadap seksual .

Wijaya (1998) mengatakan bahwa sumber daya manusia merupakan aspek yang penting bagi penyelenggaraan pemerintahan. Dalam dunia pendidikanpun sudah dikembangkan berbagai kurikulum untuk menghasilkan Sumber Daya Manusia yang handal, berkulitas, cukup kuantitas dan bermartabat. Sudah dibentuk berbagai forum perlindungan anak, sudah ada kebijakan dari pemerintah tentang perlindungan anak, sudah ada himbauan berupa spanduk, baliho dalam memberikan terhadap anak. Lengkap sudah secara struktur dengan hasil kekurangan dalam evaluasi input.

Dalam analisis terhadap hasil dari dikeluarkannya kebijakan publik oleh pemerintah, masih belum memberikan hasil yang sempurna. Segi input terdapat hampir semua komponen mulai tenaganya, sarana dan prasarana, metode, dana kurang. Dari proses baru terpusat ke hasil pencegahan tersier. Setelah tejadi kasus, baru semua aparat, orang tua menyampaikan di media massa, minta perlindungan, sampai pertanggungjawaban. Dari sisi output baru kita kaget dengan makin meningkatnya jumlah kasus. Apanya yang harus kita perbaiki. Apakah di hilir atau dihulu?

Memperhatikan kondisi ini mari kita lihat dampak apakah yang akan terjadi dengan meningkatnya kasus kekerasan seksual terhadap anak. Kasus kekerasan Seksual pada anak harus lebih mengutama upaya promotif, preventif, tanpa mengesampingkan tindakan curatif dan rehabilitatif. Hasil penelitian di atas dari segi inftrastruktur saja kita belum maksimal, tempat privasi yang tidak ada, dana yang kurang. Dari segi proses kita lebih pada pencegahan secara sekunder, belum optimal pada pencegahan secara primer.

Johan Yoga(2017) menyampaikan pendidikan anak sekolah saat ini berorientasi pada pemberian rangking. Di negara lain hal ini sudah lama ditinggalkan dan dialihkan pada pendidikan yang berorientasi pelada mutu siswa.Kualitas siswa juga diarahkan kepada prinsip Student Center Learning. Siswa tidak hanya menerima dari guru, mencatat dan menghafal untuk ujian. Tetapi harus terlaksana perubahan pola pikir atau mindset. Moral adalah kebutuhan yang mutlak harus dimiliki siswa atau mahasiswa. Prinsip pemahaman morak harus mengikuti 3 prinsip yaitu "knowing moral", fill in moral" dan "aplication moral".

Memperhatikan prinsip promosi kesehatan ada 3 strategi yang dapat digunakan, yaitu Advokasi, bina suasana, dan pemberdayaan masyarakat. Advokasi diarahkan pada pengambil kebijakan dengan pendekatan kepada stakeholdel terkait. Untuk Hukum kesehatan masyarakat seperti pencegahan kekerasan seksual, solusi terhadap perlindungan anak-anak dari kekerasan seksual adalah pada kebijakan yang lebih memperbaiki kebijakan lama. Inovasi aplikasi pesan-pesan terhadap perlindungan diri, bentukbentuk kekerasan seksual pada anak, bisa diatur kembali. Adanya "discruption" terhadap tatanan lama bisa memberikan perkembangan yang positif dalam mengatasi satu persoalan kesehatan. Hal ini sejalan dengan hasil penelitian Hayatul Rahmi (2018) yang dengan instagram, pengetahuan mahasiswa lebih baik dari pada cara sosialisasi tata muka biasa.

Tantangan terhadap pencegahan primer dengan menggunakan teknologi informasi ini, juga sejalan dengan penelitian Ayulia Fadila Sari yang meneliti (2018) tentang Pemanfaatan Media Teknologi Informasi tentang kesadaran Pemeriksaan Payudara Sendiri melalui Instagram, Whats up (WA). Peningkatan pengetahuan melalui WA mean diference 1,34 dan Instagram 0,04. Perubahan sikap melalui WA 2,92 dan Instagram 1,31 serta Persepsi audience melalui WA 5,67 dan Instagram 4,18. Berhubungan dengan sasaran dari yang digunakan adalah siswa dan mahasiswa yang rata-rata sudah mengenal 2 aplikasi teknologi informasi ini, maka dapat dipedomani untuk promosi kesehatan dalam bentuk bina suasana.

\section{Simpulan dan saran}

Kemajuan revolusi industi 4,0 suatu tantangan perubahan fixed mind set kepada future mind set dengan berbagai inovasi pencegahan kekerasan seksual pada anak. P2TP2A perlu kerjasama dalam pencegahan primer kekerasan seksual pada anak dengaan semua sekolah, institusi kesehatan, sasaran termasuk guru dan orang tua. Inovasi dalam perluasan sasaran, teknik penyampaian bisa disesuaikan dengan teknologi yang berkembang. Pemerintah daerah membuat kebijakan, menyediakan anggaran yang cukup, dan peran aktif instansi terkait termasuk Kesehatan. 


\section{Daftar Rujukan}

Ayulia Fadila Sari (2018). Pemeriksaan Sadari Menggunakan Media Sosial terhadap peningkatan pengetahun, sikap dan,2016, persepsi, Mahasiswa Unand (Fekon dan Pertanian.

Dinas Pemberdayaan Perempuan Perlindungan Anak dan Pengendalian Penduduk dan KB(2018), Laporan kasus kekerasan Terhadap Anak Kota Payakumbuh Semester I- 2 tahun 2017; DP3AP2KB

Erlinda, (2016). Upaya pendekatan perlindungan anak dari bahaya kekerasan pelecehan dan Eksploitasi , http://usd.ac.id/fakultas (diakses tanggal 25 Oktober 2017)

Hayatul Rahmi, (2018). Pemeriksaan Sadari Menggunakan Media Sosial Instgram, pada mahasiswa FKM Unand

Johan Yoga , Perubahan Pendidikan di Masa Depan, Fb, (2018)

Kementrian Pemberdayaan Perempuan dan Perlindungan Anak RI (2010), Prosesur Standart Operasional Pelaksanaan Standart Pelayanan Minimal Bidang Pelayanan Terpadu Bagi perempuan dan anak korban kekerasan, Jakarta

Kekerasan Seksual pada anak, www, kpai,go,id, diakses tanggal 6 Oktober 2017

Kholid A (2014), Promosi Kesehatan dengan Pendekatan Perilaku, Media dan Aplikasinya, Rajawali Press.

Marisa MP, (2017). Pengaruh Pemberian Pendidikan Kesehatan Tentang Pencegahan Kekerasan Seksual Terhadap Pengetahuan dan Sikap dalam Pencegahan Kekerasan Seksual pada Anak Sekolah TK Pertiwi VI Padang, Unand.

M. Anwar Fuadi, (2011). Dinamika Psikologis Kekerasan Seksual, Sebuah Studi Fenologi, Psikoislamika, Jurnal Psikologi Islam, Vol 8 No. 2 : 191-208

Notoatmodjo S (2012), Promosi Kesehatan dan Perilaku Kesehatan, Jakarta, Rineka Cipta.

NovianaI, (2014). Kekerasan Seksual Pada Anak : Dampak dan Penanganannya, Child Sexsual Abuse: Impact and Hending.

Pemerintah RI (2014), UU RI Nomor 35 Tahun 2014 tentang Perubahan atas UU Nomor 23 Tahun 2002 Tentang UU Perlindungan Anak.

Peraturan Menteri Negara Pemberdayaan Perempuan dan Perlindungan Anak Nomor 5 (2010) tentang Panduan dan Pengembangan Pusat Pelayanan Terpadu , Jakarta

Pusat Pelayanan Terpadu Pemberdayaan Perempuan dan Anak (2014), Anggaran Dasar Pusat Pelayanan Terpadu 2014-2017, Payakumbuh

Polda Sumatera Barat, (2017). Data Kekerasan Perempuan dan Anak, Provinsi Sumatera Barat, Polda Sumbar. 